\title{
Research on the Missile Ballistic System Simulation Based on Matlab
}

\author{
Fancheng KONG ${ }^{1}$ \\ ${ }^{1}$ Air Force Logistics Academy \\ Xuzhou Jiangsu, 221000, China \\ E-mail: chenweijiangyiwa@126.com

\section{Di ZHANG ${ }^{1}$} \\ ${ }^{1}$ Air Force Logistics Academy \\ Xuzhou Jiangsu, 221000, China \\ E-mail: chenweijiangyiwa@126.com
}

\author{
Wei $\mathrm{CHEN}^{1} *$ \\ ${ }^{1}$ Air Force Logistics Academy \\ Xuzhou Jiangsu, 221000, China \\ E-mail: chenweijiangyiwa@126.com \\ +*Corresponding author \\ Zhenzhou BAI ${ }^{2}$ \\ 295937 Troops \\ Fuxin Liaoning, 123000, China \\ E-mail: chenweijiangyiwa@126.com
}

\begin{abstract}
The paper makes research on the ballistic missile system simulation modeling and simulation of system modeling, simulation experiment, which are the computer simulation of three elements: system, model and computer. System in the paper refers to a certain type of ballistic missile system, the model includes a model of the mathematical model and simulation model after the second model, the computer is mainly refers to the use of MATLAB/Simulink software simulation computer.
\end{abstract}

\section{Keywords-missile ballistic system; system simulation; matlab}

\section{INTRODUCTION}

The system model is an abstraction of the actual system, which is used to study the function of the system and the function of the parts. Quantitative analysis system, in order to its own characteristics and internal relationships of abstracting, constructed the model of the system, to the analysis of the system into the analysis of the system model [1-2].

\section{SYSTEM ANALYSIS}

The laser semi-active homing guided missile in turn is made up of the laser seeker, the warhead module, the aft cabin and the aft instrument module. Its ballistic system consists of the guidance system, the control system, etc. [3], which adopts the speed tracking guidance law, and its working principle is shown in Fig 1.

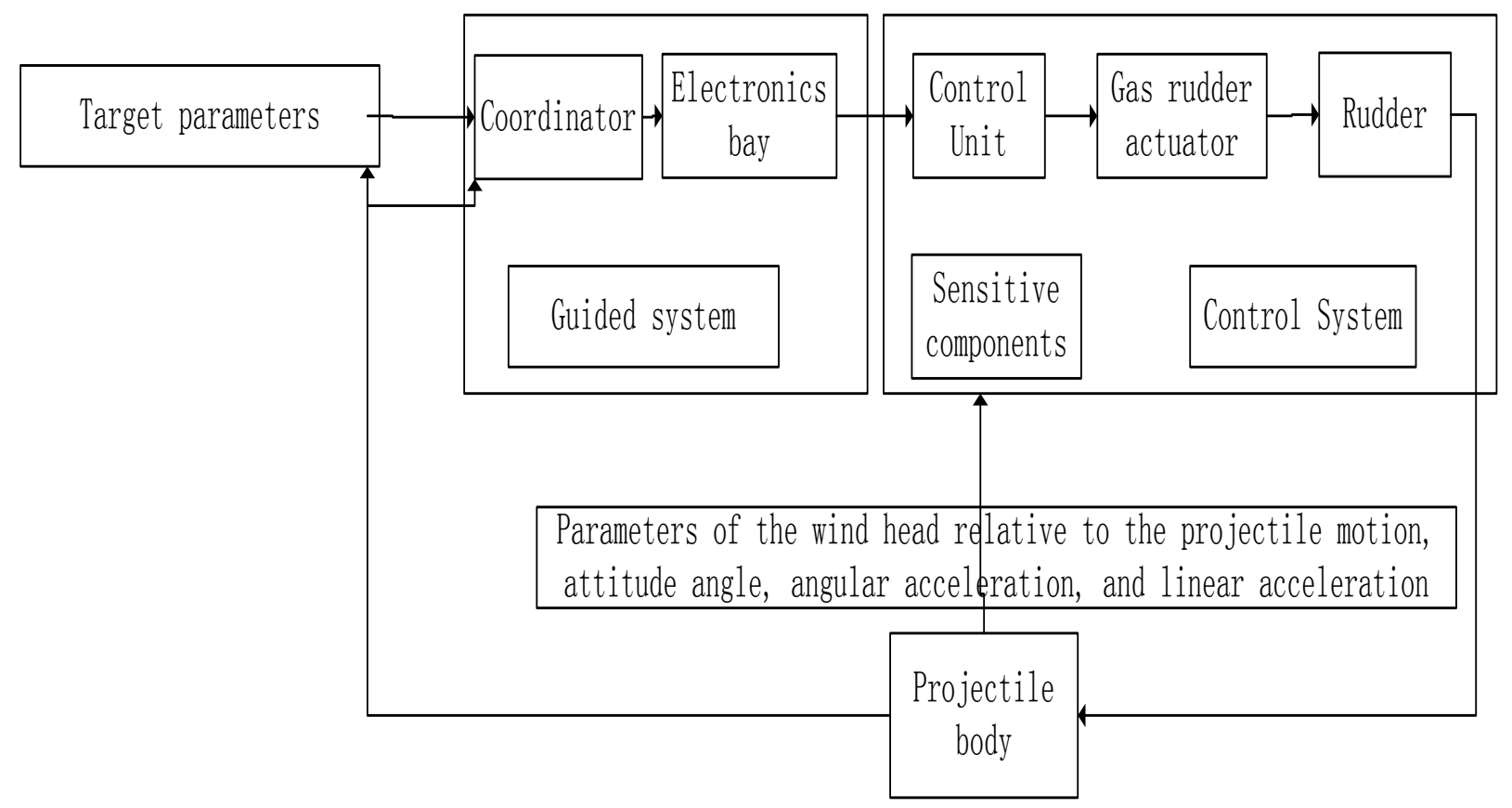

Figure 1. Laser semi-active homing guided missile structure 


\section{SySTEM MODELING}

Laser guided missile ballistic system model, the requirements of missile from bombs, capture the target, started guidance to hit the target process modeling and analyzing the trajectory of a complete system model needs to create a lot of sub models, under the condition of without considering atmospheric factors, establish system of ballistic model should include pneumatic parameter calculation model, the projectile dynamics/kinematics model, seeker model, the control system model, etc. In addition, the model and control parameter generation model can be generated according to the need. Ballistic system model is established, a common process of projectile dynamics/kinematics model, seeker model and control system model as an example, discuss the ballistic system modeling problem in system simulation.

\section{A. Projectile dynamics/kinematics models}

Mathematical simulation, the projectile dynamics/kinematics model is the most basic and most important, is usually describe bombs, aerodynamic force, gravity six degrees of freedom of the relationship between control force and moment equation of rigid body, they include bomb dynamics equation and kinematics equation and the geometric relation, etc.

\section{B. Guide head}

The seeker is the target information sensitive device on the bomb, which captures the tracking target and outputs the information needed for the guidance law. The guidance head model should accurately describe target tracking range, tracking accuracy, servo response characteristics, etc., and have the guidance information filtering function.

\section{Control system model}

Control system model describes the guidance control instruction, servo drive and the interaction between the projectile movement relations, its function is to control and stability in the bomb flying, which is a key link in the process of guidance law, was achieved by control law, the mathematical model usually includes pitch, yaw and roll three channels and the steering gear.

\section{BALlistic Simulation MODELing}

System is based on the mathematical model of the working principle of the missile ballistic model, the computer can't deal with the mathematical formula for calculating directly, therefore, must carry on the ballistic simulation, the mathematical model must be transformed into can be processed by the computer simulation model.

The main task of simulation modeling is to model the simulation process according to the characteristics and simulation requirements of the system. Based on the principle of system and the requirements of ballistic simulation, the simulation process of the laser-guided missile ballistic system is shown in Fig. 2. 


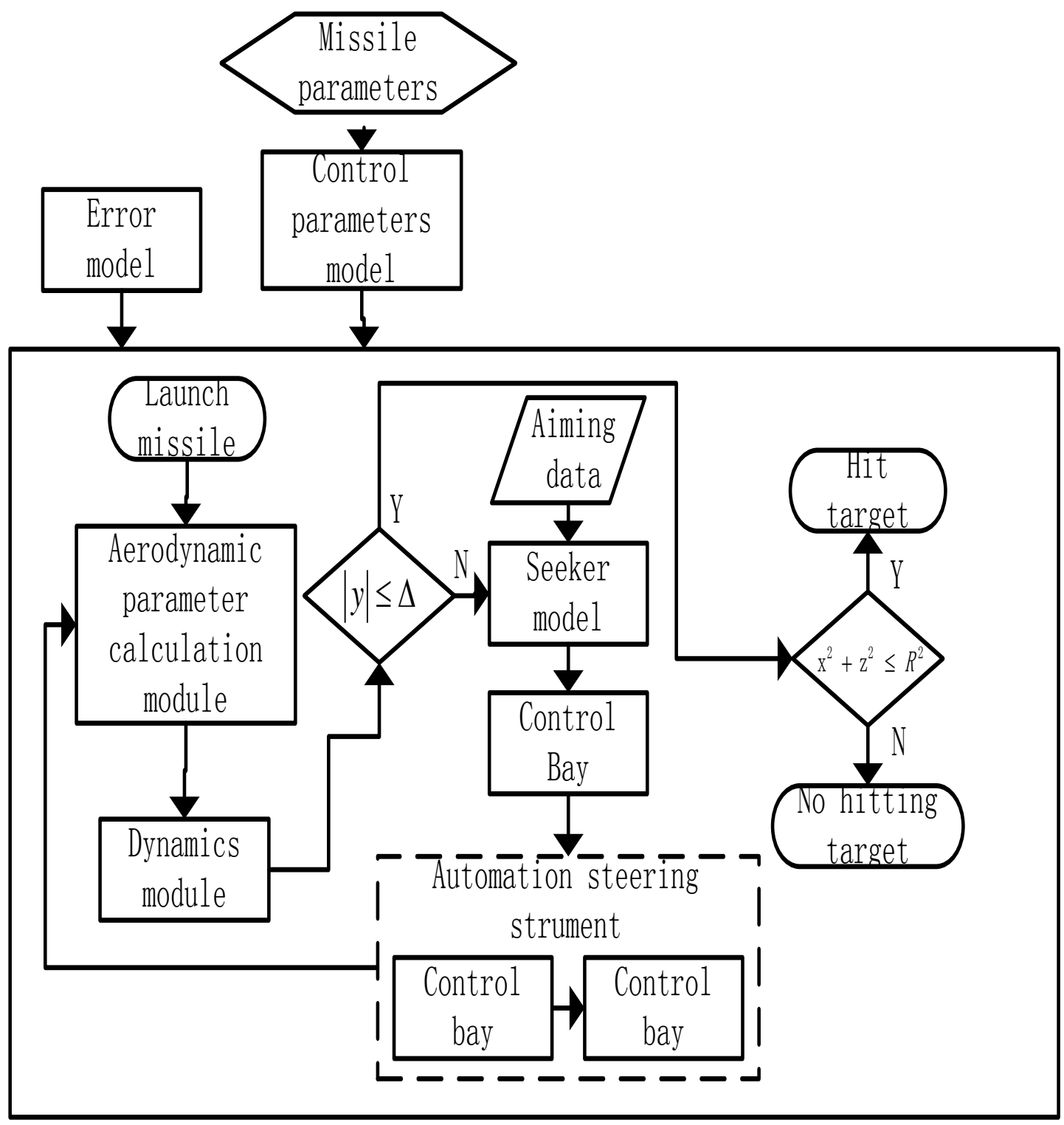

Figure 2. Laser guided missile ballistic system simulation process

Flow chart of the simulation includes kinematic/dynamic simulation module, control system simulation module, the guidance system simulation module, for this reason, this paper adopts the object-oriented simulation method, using Simulink environment of MATLAB software simulation modeling, based on dynamics of missile body/kinematics model, seeker model and mathematical model of control system model of the system by Simulink into model, realize the function of each simulation module, so as to complete 500 kilograms of laser guided bomb ballistic simulation.

\section{V.Simulation TEST}

Simulation results show that the simulation results are obtained by simulation. In order to compare the results of the simulation system and the actual trajectory, the data of simulation test are obtained under different conditions. This paper USES the MATLAB simulation software, under the environment of Simulink simulation modeling experiment, by setting the Angle of attack and velocity initial condition and parameters such as height, initial velocity and commissioning of many experiments, comparing with actual ballistic analysis, constantly optimized, finally draw the conclusion.

\section{CONCLUSION}

The paper introduces the simulation of system modeling, simulation modeling and simulation test, the analysis of the laser guided missile trajectory simulation model of the general process, has been clear about the laser guided missile trajectory simulation need to establish the mathematical model and simulation model of transformation, finally describes how simulation test. 


\section{REFERENCE}

[1] ZHANG Dong-bo, WANG Yao-nan. Fuzzy-rough Neural Network and Its Application to Vowel Recognition[J]. Control and Decision, 2013,21(2):221-224.

[2] GAO Jian,TONG Ming-an .Extracting decision rules for cooperative team air combat based on rough set theory[J].Chinese Journal of Aeronautics,2013,16(4) :223-228.

[3] CHEN Qi-shun. Calculation manual of aircraft Flight performance [M]. Beijing. Flight Mechanics journal press, 2012.

[4] S Ceccacci,C Morici,T Paneni. Conditional Probability as a Function of the Conditioning Event:Characterization of Coherent Enlargements [C]. 27th Linz Seminar on Fuzzy Set Theory,2013,35 46
[5] A.N. Steinberg,C.L. Bowman and F.E. White. Revisions to the JDL Data Fusion Model [C]. In Proceedings Of 3rd NATO/IRIS Conference,Quebec,Canada,2013

[6] D.L. Hall. Lectures in Multisensor Data Fusion and Target Tracking [C]. Xi'an, China, 2012

[7] J. Azarewzcz,G Fala and C,Heithecher. Template-Based Multi-Agent Plan Recognition for Tactical Situation Assessment [C]. In Proceedings of 5th conference on Artificial Intelligence Applications, March 2011,247 254

[8] D. Ballard and L. Rippy. A Knowledge-Based Decision Aid for Enhanced Situation Awareness [C]. IEEE/AIAA Digital Avionics Conference,2015,310 347 